\title{
Relationship between Servant Leadership and Subjective Well-Being: Evidence from Manufacturing and Services based SMEs in Pakistan
}

\author{
Raheela Maula-Bakhsh * $\quad$ Abdul Raziq ${ }^{\dagger}$
}

\begin{abstract}
Small and Medium- sized enterprises (SMEs) have emerged as building block for the growth of economies all around the globe. It has been observed that leaders and employees- both, play a crucial role for the success of any firm. In SMEs the workers and leaders work in close contact. Therefore, the success of the SME is also dependent upon such Interpersonal factors. Moreover, today's new era has emerged as posing new challenges for the leaders. For instance, emotional encounters faced by workers has deviated the dimension of employee satisfaction towards subjective facets of life satisfaction. Hence, satisfaction through (provision of affection) through interpersonal contact has gained more importance for the existing workforce in the workplace. The affective dimension of subjective well-being (SWB) has turned out to be a viable solution for such emotional traumas like distress. Similarly, servant leadership (SL) being a new concept in leadership studies has emerged as an ultimate solution for provision of employee SWB. Therefore, this study has focused its attention towards the determination of relationships between SL and the affective dimension of SWB. This study has employed a quantitative methodology. Data were collected through a self-administered survey questionnaire, which has been adapted from a previously-validated survey. The target population consisted of SMEs operating in the province of Balochistan, Pakistan. Convenience sampling was applied to collect data from 304 employees of the SME sector. The study results indicate that there is a positive significant relationship among characteristics of SL (emotional healing, empowerment and conceptualization) and the affective dimension of SWB. The study findings suggest that in order to assure success, a positive emotional state of employees should be an important consideration for SME leaders.
\end{abstract}

Keywords: SMEs, servant leadership, emotional healing, altruism, empowerment, growth of people, conceptualization, subjective wellbeing, affective dimension.

\section{Introduction}

Small and Medium Enterprises (SMEs) play a vital role in the development of many countries across the globe. SMEs add value not only in the economic development of a country but also support the development of human resources, and the subsequent creation of employments. Similarly, SMEs contribute for improvement in quality of life and living standards. Hence, their significance for socio-economic development cannot be undermined at any cost (Gibson \& Van der Vaart, 2008; Qureshi \& Herani, 2011).

Besides the fact that SMEs play a major role in the uplift of a country; the failure rate among SMEs all around the world is higher than that of larger firms, in comparison

\footnotetext{
*Assistant Professor, Department of Management Sciences, BUITEMS.

$\dagger$ Professor, Department of Management Sciences, BUITEMS Balochistan University of Information Technology, Engineering and Management Sciences, (BUITEMS) Quetta, Pakistan.
} 
(Khalique, Isa, Shaari, \& Abdul, 2011; Ullah, Shah, Hassan, \& Zaman, 2011). Economic and financial issues play a key role in the failure of these SMEs. Moreover, political, legal and managerial issues also have significant role in their failure.

In Pakistan, there is a lack of skilled labor force, which is a major challenge for the owners of small firms. The effective use of laborers is an important factor which can help an economy to grow and expand (Batool \& Zulfiqar, 2011; Khan, Awang, \& Zulkifli, 2013). In such situations, leaders can play an effective role by providing individuals with opportunities to learn and improve their work. Moreover, SMEs' leaders need to adopt a more follower-centric approach to leadership (Gul, Rehman, Razzaq, Ahmad, \& Saif, 2012; World Bank, 2015).

According to Hojman and Miranda (2018) in the existing era the concept of human well-being and development has shifted from common extrinsic factors like income and compensation. Now the focus has been moved towards emphasis on more dynamic and multi-facet approach which includes role of freedom, opportunities, and social inclusion. Additionally Macik-Frey, Quick, and Cooper (2009) narrated that the well-being of workers and rapid innovations are becoming the foremost concerns for the firms. Subsequently, the significance of highly ethical and considerate leadership has been amplified. It has been observed that every individual nowadays is seeking a job where the leadership can offer them a purposeful and healthy life (Griffin, Patterson, \& West, 2001).

It is further stated by Arnetz (1999) that this demand made by employees can be realized via empowering employees. Employees can be empowered through providing them an opportunity to work independently for personal growth and to express their emotions freely (Clark, 1997). Researchers have articulated that such goals can be attained by the provision of an ethical environment, clear vision, and direction where the leadership solves the problems of employees (Arnetz, 1999; Clark, 1997; Griffin, Patterson, \& West, 2001).

Hence, the leadership factor (i.e. leadership) is also becoming a challenge for the current practices of leaders in SMEs. Some researchers have further argued that leaders may have to go beyond the motivational role by adopting a more ethical behavior to foster a healthy organizational environment (Gul et al., 2012). The concern for people and value for employees is something which is observed in the Servant Leadership Theory. Therefore, studying Servant Leadership as a determinant of SWB is both, an empirical and a necessary objective.

Servant leadership is not a new concept. However, it has never been given proper attention in its earlier stages. Greenleaf (1977) conceptualized servant leadership such that the servant-leader's motive is to provide services as a servant first. He argued that the servant leader makes sure that employees' prioritized needs are being served first and, afterwards the desire to lead automatically proceeds. Whereas, on the other hand, researchers have termed servant leadership as an extension of transformational leadership. In their view, servant leadership is one that goes further than clarifying phenomenon which is not explained by transformational leadership (Page \& Wong, 2000; Patterson, 2003). According to this theory the primary purpose of the leader in servant leadership is serving people and leading them. Hence, they further stated that effort is made to improve their well-being in order to get benefits by realizing goals and tasks for the good of 
all (Page \& Wong, 2000).

When we further look into the definition we see that servant leadership practices have potential to change the organization. Kibbe (2015) claimed it as a concept which has ability to change organization, as well as societies. It encourages both personal and organizational symbols. He further stated that it has the ability and potential to positively transform interpersonal work relations as well as to transit organizational life. Moreover, he described that this concept is generalizable.

A question arises here that who is a servant leader? Parolini (2004) theorized Servant leaders as those who have certain character attributes that includes positive orientation for people, and to give priority in ranked order. Hence he argued that priority is given first to people, then to the systems and contexts. At the end to the goals that are aimed at financial and productivity related output as well as organizational effectiveness. Maxwell (2011) claimed that a servant leader is one who wants to serve first. Here the servant leader provides services to help his subordinates for their development and growth. The mentality of a servant leader is based on I serve rather than the mentality of I lead (Sendjaya \& Sarros, 2002).

The models of servant leadership provided by a number of authors have shed light on the important attributes of servant leadership these include Page and Wong (2000); Parolini (2004); Patterson (2003); Russell and Gregory Stone (2002); Winston (2003) Whereas other researchers have further focused on both provision and explanations of the servant leadership attributes, including (Barbuto Jr \& Wheeler, 2002; Greenleaf, 1977; Parolini, 2004).

Servant leadership is based on specific characteristics of servant leaders which differentiate him/her from other leaders. By doing extensive research (Russell \& Gregory Stone, 2002) have found 20 attributes of servant leadership which were further divided by them into two categories such as functional attributes and accompanying attributes.

However in this study five attributes (Emotional Healing, Altruism, Empowerment, Growth of People and Conceptualization) have been selected. These attributes have been used in different studies conducted by Liden, Wayne, Zhao, and Henderson (2008); Panaccio, Donia, Saint-Michel, and Liden (2015).

Employee well-being is quite a fascinating aftermath that has its focus beyond motivation rather it pays attention towards the positive health of employees. It has been observed by the researchers that the purpose of servant leadership is to improve the wellbeing of followers therefore subjective well-being is another variable of research concern (Bass, 2000; Page \& Wong, 2000). According to researchers, Subjective well-being (SWB) is referred as the evaluation of peoples' lives by themselves. They further stated that the form can be cognitive or based on emotional impact (Diener, Colvin, Pavot, \& Allman, 1991).

Similarly, researchers have elaborated that SWB is essential in the sense that dissatisfaction, depression and negative events encountered by a person will never enable him/her to mark his/her life as an ideal one. The feeling of wellbeing has been considered as an important predictor of SWB of a person's life (Dolan, Peasgood, \& White, 2008; Klonowicz, 2001). In SWB Affect is defined as comprising of vast array of feelings, affect has two components moods and emotions. Therefore, affective dimension deals 
with these two components.

The question arises that whether Servant Leadership has any impact on Affective Dimension of SWB or not? It has been observed that every individual nowadays is seeking that kind of job where the leadership can offer them purposeful and healthy life (Griffin et al., 2001). It is stated by Arnetz (1999) that this demand made by employees can be realized via empowering employees. Employees can be empowered through providing them opportunity to work independently for personal growth and to express their emotions freely (Clark, 1997).

Researchers have articulated that such goal can be attained by provision of an ethical environment, clear vision, and direction where the leadership solves the problems of employees (Arnetz, 1999; Griffin et al., 2001). This in return is the basic tent of servant leadership.

It has been theorized by Neubert, Hunter, and Tolentino (2016) that although servant leadership is considered beneficial for community in which they work however there is a great need to develop linkages that whether this servant leadership phenomenon can be used to enhance well-being of followers, organization and community or not. In addition, Maula-Bakhsh and Raziq (2013) has also posited positive linkages between servant leadership and SWB.

So, this empirical study will contribute both theoretically and methodologically. As theoretically, it will try to add more support for the concept suggested by Burke, Page, and Cooper (2015). On the other hand, the methodological contribution will test the linkages proposed by Maula-Bakhsh and Raziq (2013). Therefore, the major focus of this study to examine the positive relationship between Servant leadership and Affective Dimension of SWB, the context of SMEs. This study will discover the effect of characteristics of Servant Leadership (Emotional Healing, Altruism, Empowerment, Conceptualization, and Growth of People) on Affective dimension of SWB. The study will further find the impact of Servant Leadership on Subjective well-being of employees in the SMEs Sector.

\section{Literature Review}

\section{Servant Leadership}

It has been evidenced that highly stressed conditions are reducing positive emotional encounters hence impending well-being. Positivity from employee's emotion is also ripped off through pressure of work (Marzuki, 2013). Further, Harter, Schmidt, and Keyes (2003) argued that in order to foster positive emotions among workers, management along with leadership need to take particular initiatives. The initiatives according to them may possess ability to backup for outcome anticipations, and accessibility of physical resources. Along with these they further posited that for contribution and achievement of goals individuals must be encouraged.

It has been posited that the primary purpose of leader in servant leadership theory is serving people and leading them. Further researchers argued that leader tries to improve well-being of his/her employee and in return attain benefits by realizing goals and tasks 
for the good of all (Page \& Wong, 2000).

Empirical studies have been conducted on servant leadership all around the world. Some of them have tested the servant leadership models while others have used different dimensions of servant leadership. For instance, Barbuto Jr and Hayden (2011) conducted a research to find the relationship between servant leadership and leader member exchange (LMX). In their study they used five dimensions (wisdom, persuasive mapping, altruistic calling, emotional healing and organizational stewardship) of servant leadership. They tested the usefulness of such dimensions in enhancement of leader member exchange quality. Although they found strong correlation among them however did not work on the end result of such a relationship.

Barbuto and Gifford (2010) examined the use of five characteristics of servant leadership by males and females over the agentic and communal properties of servant leadership. Their study revealed that there was no difference in the use of five dimensions (altruistic calling, emotional healing, wisdom, persuasive mapping, and organizational stewardship) among males and females.

Barbuto Jr and Wheeler (2006) worked on 11 dimensions of servant leadership and came up with results that for followers' leader wisdom was a most promising construct. They observed that for leaders, organizational stewardship was the most influential construct. They observed that among these attributes altruistic calling, emotional healing, and persuasive mapping also had significant relation with transformational leadership, LXM, additional struggle, as well as organizational effectiveness.

In Pakistan, Gul et al. (2012) worked on the impact of leadership style on organizational commitment where they studied both servant leadership and transformational leadership. Further, they came up with the result that servant leadership does not affect organizational commitment. They observed that transformational leadership was having a clear and direct association with organizational commitment.

Abid, Gulzar, and Hussain (2015) analyzed the relationship of servant leadership with organizational citizenship behavior (OCB). In their research, trust was used as moderating variable and results affirmed that servant leadership does have positive impact on workers OCB. Further, Hussain and Ali (2012) investigated the influence of servant leadership on worker performance. The dimensions they included in research were empowerment, trust, agapao love (i.e. unconditional love), humility and vision. The study outcomes supported the notion that servant leadership has significant impact on workers performance.

\section{Subjective Wellbeing}

Marzuki (2013) argued that emotional encounters are part of family and work life of the people. These experiences can be the primary origin of positive as well as negative ones. Consequently, arousal of positive emotions (i.e. pleasure, love, belief, and promise) mends the body functioning. Conversely, if emotions are negative these may cause harm to the wellbeing of people.

There are different consequences of SWB. It has been found by prior studies that work life satisfaction accounts for one fourth of total variation in overall life satisfaction in human life (Marzuki, 2013; Spector, 2012). Diener and Chan (2011) claimed that SWB im- 
pacts health and longevity where PA is positively related to health and longevity while NA has detrimental effect on these. They stated that stress, depression and diseases are reduced by positive moods and feelings.

Moreover, it is further observed that for the enhancement of workers well-being leaders and managers gone through several specialized development programs. These include worker appreciation practices, free of cost support programs and health assistance programs for workers. Accordingly, leaders impart substantial organizational resources for this purpose (Rynes, Colbert, \& Brown, 2002).

It has been argued earlier that employees spend majority of their time at workplace. Thus, their life satisfaction is greatly influenced by work life satisfaction (Campbell, Converse, \& Rodgers, 1976). It is evident that many factors contribute to the worker's health including supervisory, work repetition, and complexity related to task (Bastian, Kuppens, De Roover, \& Diener, 2014; Griffin et al., 2001). Joshanloo (2017) studied the relationship of externality of happiness, SWB and mediational role of personality and psychological resilience. In this study the results partially supported the hypothesis that when personal growth initiatives are believed to be externally created then this externality of happiness is negatively associated with SWB while keeping personality and psychological resilience mediators.

Further, it has been witnessed that positive emotions are the main drivers in generation of life satisfaction which in return is accounted for the overall SWB of employees (Bastian et al., 2014).

Majority of organizations according to Harter et al. (2003), have highly stressing working conditions where employees are too much pressurized which in return reduces constructive emotional involvement. Their study observed that such reduction in emotional involvement is a barrier for well-being of employees. They further argued that positive emotional involvement is facilitated by certain management support providing actions like providing encouragement, sense of belongingness and opportunity of growth encouraging employees to contribute to full extent.

On the other hand, servant leadership has been articulated as servant-hood, where follower's needs are placed ahead of leader's self-interest (Greenleaf, 1977; Maxwell, 2011). Sims (2005) advanced the idea by considering servant leadership as a way to honor workers self-esteem and providing value to employees. The study further stated that leader stimulates innovative and distinct power within himself/herself and also among individuals to the possible level.

Servant leadership is completely different from other forms of leadership. This difference is based on servant leader's characteristics (Russell \& Gregory Stone, 2002). Thus, the characteristics of servant leadership and their possible links are discussed as follows.

The prominent traits which are considered important in improving the well-being of employees includes emotional healing, altruism empowering, conceptualization, and growth of people (Liden et al., 2008; Parolini, 2004; Spears, 2010).

The ability of a servant leader to know about employee's emotional problems and to know well, how to encounter and heal them is known as emotional healing (Barbuto Jr \& Wheeler, 2002). As articulated that "identification of emotional problem and provision of right kind of remedy will lead towards arousal of positive affect. Whereas when servant 
leader fails in healing process it will lead to negative Affect" (Maula-Bakhsh \& Raziq, 2013). Putting the subordinate first (Altruism) suggest that the servant leader instead of working for self-interest, chooses serving others (Greenleaf, 1977).

$H_{1}$ : There is a significant positive relationship between Emotional Healing and Affective dimension of $S W B$.

Putting the subordinate first (Altruism) suggest that the servant leader instead of working for self-interest, chooses serving others (Greenleaf, 1977).Considering the altruism researchers argued that "when leader provides services to others it will generate positive feelings and emotions among followers. However, if servant leader is unable to provide support and services it will lead to negative emotions" (Maula-Bakhsh \& Raziq, 2013). SWB.

$H_{2}$ : There is a significant positive relationship between Altruism and Affective dimension of

Laub (1999) conceptualized that by empowering workers leader develops prospective employees who can play vital role in organization success. Maula-Bakhsh and Raziq (2013) has posited that through sharing power and authority with subordinates leader can foster positive affect among them. On the other hand under autocratic style of leadership where only one person has the charge of all matters, the leadership can raise negative affect.

$H_{3}$ : There is a significant positive relationship between Empowerment and Affective dimension of $S W B$.

Barbuto Jr and Wheeler (2002) narrated growth of people is concerned with helping individual to learn and go beyond their current capabilities. Servant leadership theory conceptualize that the ability of employees to contribute in organization is higher than the leaders ability to contribute. For this reason, the abilities of employees need to be explored by providing them with the opportunity to grow. Researchers enunciated that "when leader identifies the potential for improvement among his followers and provides them opportunities of development it facilitates their emotional health" (Maula-Bakhsh \& Raziq, 2013).

$H_{4}$ : There is a significant positive relationship between Growth of people and Affective dimension of $S W B$.

Conceptualization according to researcher is the ability of a servant leader to think beyond current working of organization. Furthermore, servant leadership entails that servant leader must amplify his thinking outside of present functioning besides immediate goals. The balance between current goals and prospective thinking needs to be maintained by servant leader (Spears, 2005, 2010). Therefore, it has been posited by Maula- 
Bakhsh and Raziq (2013) when the leaders has ability to envision future and to look beyond current workings then it will generate positive affect among subordinates.

$H_{5}$ : There is a significant positive relationship between Conceptualization and Affective dimension of $S W B$.

The following Model has been constructed on the basis of literature review and link proposed in Maula-Bakhsh and Raziq (2013).

Figure 1

Theoretical Framework of SLQ and SWB

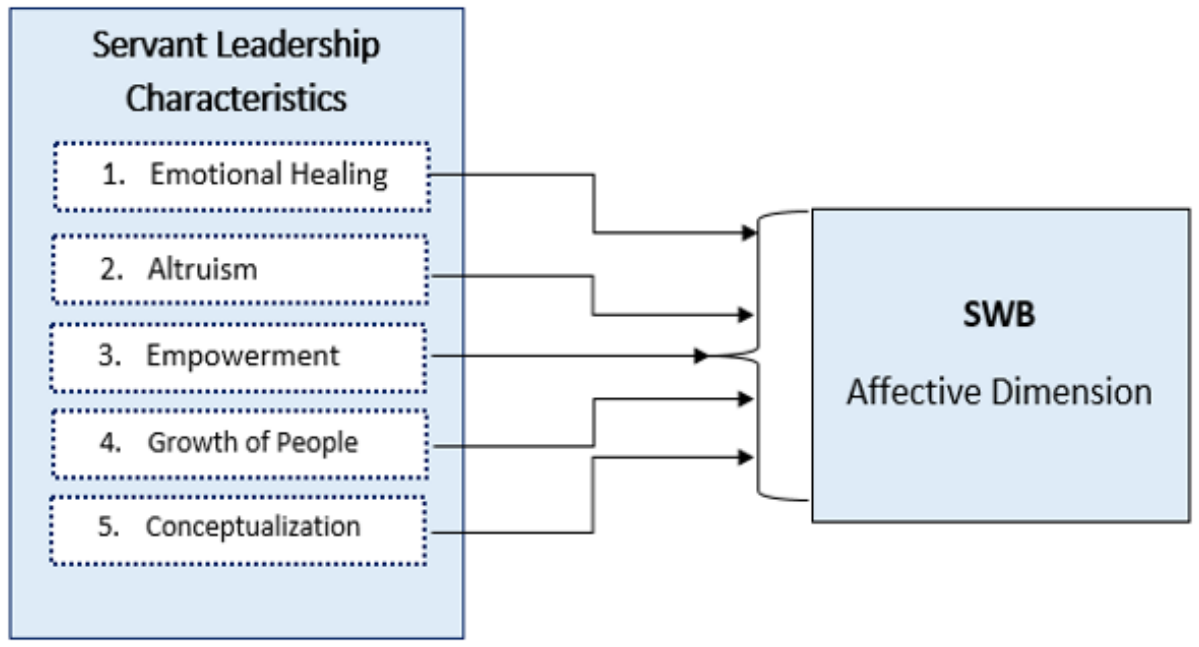

\section{Methodology}

\section{Population and Sample Size}

On the basis of importance of SMEs discussed in literature, the target population for this study is SME Sector of Balochistan, the largest province of Pakistan (in terms of land mass) where both services and manufacturing sectors are included.

The SMEDA criteria for SMEs categorization has been used which mentioned that for small and medium size firms, number of employees should be less than 250 (SMEDA, 2007). However, organizations with less than 10 employees are also excluded for data collection purpose. It is due to the reason that micro organizations lack proper organizational structure (Raziq, 2011).

As indicated by Khurrum, Rana, and Asad (2008); Raziq, Wiesner, et al. (2016) that there is unavailability of sampling frame for SMEs in Pakistan that covers all SMEs, so it is not possible to use probability sampling. As a result, non-probability convenience 
sampling has been used because it is more convenient to implement and also less expensive. Another reason is that it is used in situations where population is not well defined or there is inability to determine the sampling frame (Saunders, Lewis, \& Thornhill, 2009; Sekaran \& Bougie, 2016). In non-probability convenience sampling technique, sample size is selected by the researcher on the basis of convenience (Mazzocchi, 2008).

There are many methods to calculate sample size. Barlett, Kotrlik, and Higgins (2001) provided a table for calculation of accurate sample size based on alpha levels and a set error rate. $G$ Power is another statistical tool which can be used to determine accurate sample size by considering effect size and alpha level (Barlett et al., 2001). However, in this study the sample size has been selected on the basis of criteria set for application of data analysis tests (factor analysis and multiple regression analysis). It has been argued by MacCallum, Widaman, Zhang, and Hong (1999) that; for factor analysis the sample size should be 300 . In addition, it has been further suggested by researcher that the sample size of 300 is good for the factor analysis (Comrey \& Lee, 2013).

Correspondingly it has been discussed that, to apply regression analysis for each independent/ predictor variable there should be at least 10 observations (Sekaran \& Bougie, 2016; Hair Jr, Black, Babin, \& Anderson, 2010). Initially 675 questionnaires were distributed. However, only 304 questionnaires were returned. Thus, the response rate was 51 percent.

\section{Data Instrument and Data Analysis Techniques}

For collecting data about Servant Leadership, questionnaire composed of 28 items was adapted from (Liden et al., 2008). As questions on only five dimensions of SLQ were taken in the study based on need to assess only these dimensions (Emotional Healing, Altruism, Empowerment, Growth of People and Conceptualization). It has been suggested by Malhotra and Birks (2006) that items or questions can be dropped from the questionnaire if the study requires such change. However in this case validity and reliability should be rechecked.

Whereas for Affective Dimension of Subjective well-being (SPANE) based on 12 items were adapted (Diener et al., 2009). Seven point Likert scale has been used in SLQ and five point Likert scale were used for SPANE. However, SPANE was converted on a seven point likert scale in order to standardize scale in questionnaire and for meeting the assumption for regression analysis.

There were many reasons for performing this activity. Firstly, it has been articulated by Malhotra and Birks (2006) that the standardization of the scale in a questionnaire is a form of scale transformation process. They have discussed that the process is conducted to confirm the compatibility of one scale with other scale under use. Secondly, Vaus (2002) considered it desirable to measure an attitudinal concept on a wide dimension. Thirdly, the motive was to gain insight about attitudes of respondents in wide dimension. As suggested by Malhotra and Birks (2006) and Vaus (2002) that in order to collect information about attitudes and to attain variability in responses the scales used in research must contain widespread length.

In this piece of literature as the questionnaire was adapted so for that reason FA was 
used. For FA the data set consisting of sample size $n \geq 50$ is used.. As the nature of study was explanatory and the objective of this study was to determine the relationship of servant leadership and affective dimension of subjective wellbeing so, correlational analysis was performed. In addition, as Field (2009) suggested that for predicting variable we use a technique called regression analysis. For this study, with the help of SPSS, multiple regression analysis was performed.

\section{Results}

The valuable responses of employees from SMEs are presented below in the tables. These responses highlighted the importance of servant leadership for enhancement of wellbeing through affective dimension.

The tables given below, exhibit valuable insights about the data collection phase.

\begin{tabular}{lcccc}
$\begin{array}{l}\text { Table } \mathbf{1} \\
\text { Sector wise Statistics }\end{array}$ & Frequency & Percentage & Distributed & Returned \\
\hline & 18 & 60 & & \\
\hline $\begin{array}{l}\text { Service sector firms } \\
\text { Manufacturing sector firms }\end{array}$ & 12 & 40 & & 304 \\
$\begin{array}{l}\text { Questionnaires } \\
\text { Total }\end{array}$ & 30 & 100 & 675 & \\
\hline
\end{tabular}

The data were collected from both manufacturing and services sector SMEs. Among these 30 organization, 18 (60 percent) were service firms including schools, colleges, universities, telecom franchises, automobile franchises, hotels, and hospitals. Further, remaining 12 (40 percent) organizations belong to manufacturing sector including firms related to marble, chemical, timber, glassware, electronics and food industry.

Table (2) depicts that for 20 questions of the Servant Leadership Questionnaire, the consistency was 89.3 percent whereas, for Scale of Positive and Negative experience the consistency values are 71.2 percent respectively. These values for consistency of scales makes collected responses more valuable. Hence, reliability result shows that the data is appropriate to analyze the relationship between Servant Leadership and Subjective Wellbeing of employees.

The data comprised of 304 employees indicate that 44.7 percent of them belong to age group 21-30, 33.6 percent belong to age group 31-40, whereas remaining 21.7 percent were from age group $41 \&$ above. Out of 304 employees, 71.1 percent were males and 28.9 percent were females. The industry wise statistics shows that 67.1 percent respondents were from services and 32.9 percent were from manufacturing sectors. Within service sector there were 57.4 percent males and 42.6 percent females however where as in manufacturing sector there were 99 percent males and one percent female respondents. 
Table 2

Demographic and Reliability Statistics

\begin{tabular}{|c|c|c|c|c|}
\hline & Frequency & $\begin{array}{c}\text { Percentage } \\
\%\end{array}$ & $\begin{array}{l}\text { No of } \\
\text { Items }\end{array}$ & $\begin{array}{c}\text { Cronbach's } \\
\text { Alpha }\end{array}$ \\
\hline \multicolumn{5}{|l|}{ Age } \\
\hline $21-30$ & 136 & 44.7 & & \\
\hline $31-40$ & 102 & 33.6 & & \\
\hline $41 \&$ above & 66 & 21.7 & & \\
\hline Total & 304 & 100 & & \\
\hline Gender & 216 & 71.1 & & \\
\hline Male & 88 & 28.9 & & \\
\hline \multicolumn{5}{|l|}{ Female } \\
\hline Total & 304 & 100 & & \\
\hline Sector & 204 & 67.1 & & \\
\hline Services & 100 & 32.9 & & \\
\hline \multicolumn{5}{|l|}{ Manufacturing } \\
\hline Total & 304 & 100 & & \\
\hline \multicolumn{5}{|l|}{ Gender within sectors } \\
\hline \multicolumn{5}{|l|}{ Services } \\
\hline Male & 117 & 57.4 & & \\
\hline Female & 87 & 42.6 & & \\
\hline Total & 204 & 100 & & \\
\hline \multicolumn{5}{|l|}{ Manufacturing } \\
\hline Male & 99 & 99 & & \\
\hline Female & 1 & 1 & & \\
\hline Total & 100 & 100 & & \\
\hline $\begin{array}{l}\text { Servant Leadership Scale } \\
\text { (SLQ) }\end{array}$ & & & 20 & 0.893 \\
\hline $\begin{array}{l}\text { Scale of Positive and } \\
\text { Negative Experience } \\
\text { (SPANE) }\end{array}$ & & & 12 & 0.712 \\
\hline
\end{tabular}

The basic assumption for the application of parametric test is of normality (Field, 2009). The normality of data has two imperative aspects that are skewness and kurtosis (Malhotra \& Birks, 2006). The values of skewness and kurtosis ranges from -.452 to .290 and -.134 to -.847 respectively. Therefore, results implies that data is normally distributed across the mean and assumption of normality of the data is satisfied (Hair Jr et al., 2010).

\section{Results from EFA}

EFA was run with Varimax rotation (orthogonal). In the rotated component matrix (Table 3 ), there were five questions which were removed due to improper factor loadings (factor loadings < 0.40) (Hair Jr et al., 2010). These questions are: "He/She cares more about others' success than his/her own", "He/She can sacrifice his/her own interest to meet others' need", "He/She wants to know about others career goal", "He/She does what he or she can to make others job easier", and "He/She puts others' interest above his/her own". 
Table 3

Rotated Component Matrix for SLQ

\begin{tabular}{lc}
\hline Items & Factor \\
\hline Emotional Healing (Cronbach's $\alpha=\mathbf{0 . 7 3 0}$ ) & \\
Other would seek help from him/her if they had personal problem & 0.776 \\
He/ She Cares about Personal well being & 0.861 \\
He/ She takes time to talk to others on a personal level & 0.682 \\
He/ She can recognize when others are feeling down without asking them & 0.603 \\
\hline Empowerment (Cronbach's $\alpha=\mathbf{0 . 6 8 9})$ & 0.567 \\
He/ She gives other the responsibility to make important decisions about their own jobs & 0.739 \\
He/ She encourages others to handle important work decisions on their own & \\
He/ She gives others the freedom to handle difficult situations in the way they feel is best & 0.691 \\
If other needs to make important decisions at work, they do not need to consult him/her & 0.759 \\
\hline Growth of People (Cronbach's $\alpha=\mathbf{0 . 6 8 2})$ & 0.555 \\
He/ She makes other's career development a priority & 0.700 \\
He/ She is interested in making sure other reach their career goals & 0.793 \\
He/ She provides others with work experiences that enable them to develop new skills. & \\
\hline Conceptualization (Cronbach's $\alpha=0.702)$ & 0.748 \\
He/ She can tell if something work related is going wrong & 0.792 \\
He/ She is able to think through complex problem & 0.668 \\
He/ She has a thorough understanding of the organization and its goal & 0.601 \\
\hline He/ She can solve problems with new or creative ideas
\end{tabular}

Therefore, five dimensions of servant leadership were reduced to four dimensions. The remaining 15 questions were loaded under the four dimensions named as Emotional healing, Conceptualization, Empowerment, \& Growth of people. On the emotional healing four questions were loaded significantly. The next three questions were loaded significantly on the growth of people dimension. Further four questions were loaded on the empowerment. The remaining four questions significantly loaded on the conceptualization.

EFA was run on SPANE (see Table 4). All items were significantly loaded on single dimension with satisfactory loadings (above 0.40 ). It is clear from Table 4 that only single construct has eigenvalue above 1 which shows that this single construct represents maximum variance (62.07 percent) and scale is unidimensional (Tabachnick \& Fidell, 2007).

Table 4

Rotated Component Matrix and Eigen Values SPANE

\begin{tabular}{lc}
\hline & SPANE \\
\hline Positive & 0.809 \\
Good & 0.889 \\
Pleasant & 0.868 \\
Happy & 0.84 \\
Joyful & 0.752 \\
Contended & 0.505 \\
\hline
\end{tabular}

\section{Results from CFA}

For the application of CFA six stages were followed as prescribed by Hair Jr et al. (2010). First of all EFA was carried out which resulted in four factors (comprising of fifteen items). Secondly, reliability for each scale was checked through Cronbach's Alpha (Field, 2009; Hair Jr et al., 2010). 
Table (5) shows composite reliability (CR) and average variances contributed by each variable (using Excel Statistical Package). The values of CR for all variables are above 0.7 for all dimensions of SLQ and above 0.6 for SPANE, which indicates that constructs have adequate level of internal consistency as given by Hair Jr et al. (2010).

Table 5

Composite Reliability, Discriminant Validity

\begin{tabular}{lcccccc}
\hline & \multicolumn{3}{c}{ SLQ } & \multicolumn{3}{c}{ SPANE } \\
& CR & AVE & MSV & CR & AVE & MSV \\
\hline Emotional Healing & 0.838 & 0.565 & 0.42 & & & \\
Conceptualization & 0.81 & 0.517 & 0.576 & & & \\
Empowerment & 0.814 & 0.523 & 0.576 & & & \\
Growth of people & 0.702 & 0.446 & 0.42 & & & \\
SPANE-P & 0.681 & 0.623 & & 0.681 & 0.623 & - \\
\hline
\end{tabular}

According to Hair Jr et al. (2010) discriminant validity displays distinctiveness of constructs in analysis. Additionally, in order to check discriminant validity there are two criteria one is that the value of AVE should be greater than squared correlation that is Maximum Shared Variance (MSV) of any two constructs. Second one is that, if the correlation among any two construct is equal to 1.0 they do not represent separate construct, and correlation below 1 even of 0.9 can still produce significant difference between two constructs.

As discussed by Kline, Sulsky, and Rever-Moriyama (2000) the correlation of constructs on one to one basis must be less than 0.85. The values of MSV for SLQ in Table (5) are less than ASVE except for conceptualization and empowerment which shows less support for the discriminant validity. However, in Table (6) the correlation between any two constructs of SLQ is less than 0.85 for all factors which verifies discriminant validity.

Furthermore, for positive affect only SPANE-P was used which is unidimensional construct therefore, discriminant validity cannot be calculated.

Table 6

Correlations among Constructs of SLQ

\begin{tabular}{lcccc}
\hline & Conceptualization & Emotional healing & Empowerment & Growth of people \\
\hline Squared correlation & & & & \\
Conceptualization & 1 & & & \\
Emotional healing & $0.400^{* *}$ & 1 & 1 & \\
Empowerment & $0.413^{* *}$ & $0.759^{* *}$ & $0.431^{* *}$ & 1 \\
Growth of people & $0.648^{* *}$ & $0.265^{* *}$ & &
\end{tabular}

Convergent validity determination is the fourth step which shows convergence of items on a single factor. The convergent validity is assessed through factor loadings (Fornell \& Larcker, 1981). From the Measurement Model in Figure (2) it is clear that factor loadings for all items of SLQ, are greater than 0.50 which is in acceptable range (Hair Jr et al., 2010).

On the basis of Factor loadings in CFA one item (He/she wants to know about others' career goal) that had factor loading below 0.5 has been excluded from growth of people dimension in SLQ scale. 


\section{Figure 2}

Measurement Model Results for CFA of SLQ

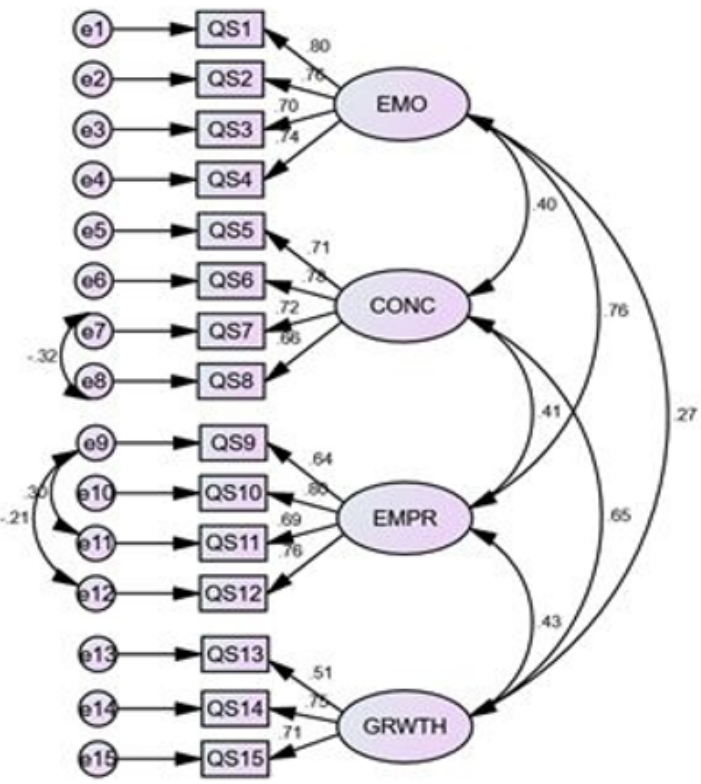

Additionally from Measurement Model in Figure (3) the factor loadings also confirms convergent validity of the SPANE items. Here, one item (contended) has been dropped due to low factor loading from SPANE scale.

\section{Figure 3}

Measurement Model Results for CFA of SPANE

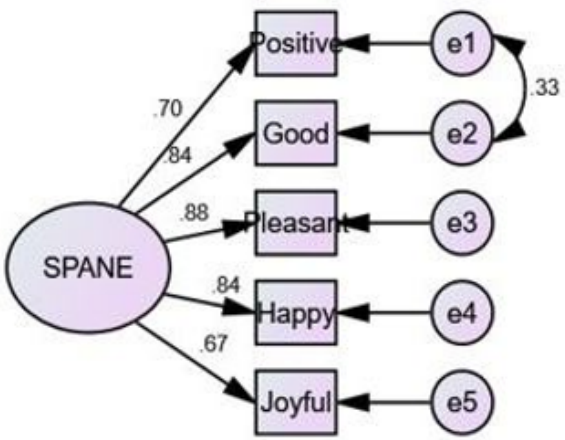

The fifth step is to check the model fit through CFA for all exogenous models. In order to assure that the exogenous model is a good fit many indexes are used, however the major criteria used to assess the absolute model fit or goodness of fit in this research 
are Chi-Square test $\left(\chi^{2}\right)$, relative/normed Chi-Square CMIN/d.f, and Root Mean Square Error of Approximation (RMSEA).

Table (7) represents values for model fit and their acceptable range by considering Hair Jr et al. (2010); Tabachnick and Fidell (2007) criteria.

\begin{tabular}{lccc}
$\begin{array}{l}\text { Table } 7 \\
\text { Measurement Models Fit Statistics }\end{array}$ & & \\
\hline Fit statistic & Acceptable Range & Actual Output SLQ & Actual Output SPANE \\
\hline$\chi^{2}$ & - & 186.317 & 73.683 \\
Df & - & 81 & 32 \\
$\chi^{2}$ significance & $\mathrm{p}>0.05$ & 0 & 0.122 \\
$\chi^{2} / \mathrm{df}$ & $<5.00$ & 2.3 & 1.821 \\
GFI & $>.90$ & 0.924 & 0.991 \\
CFI & $>.90$ & 0.942 & 0.996 \\
RMSEA & $<.08$ & 0.066 & 0.052 \\
\hline
\end{tabular}

The values in Table (10) shows that both measurement models have turned out to be good fit as all values (for $\chi^{2} / \mathrm{df}, \mathrm{GFI}, \mathrm{CFI}$, and RMSEA) are in acceptable range for SLQ and values (for Chi-Square, $\chi^{2} / \mathrm{df}, \mathrm{GFI}, \mathrm{CFI}$, and RMSEA) are in acceptable range for SPANE scale.

The correlation among all variables was also run through SPSS. Table 11 indicate results of correlation analysis which depicts relationship among affective dimension and servant leadership characteristics (emotional healing, conceptualization, empowerment, and growth of people). It is clear from Table 8 that out of four, two variables (emotional healing, and empowerment) have significant positive relationship with the SWB (Affective dimension). Consequently other two variables (growth of people and conceptualization) have no significant positive relationship with affective dimension. Thus our two hypothesis $\mathrm{H} 1$ and $\mathrm{H} 3$ are accepted. On this basis we can say that there is a positive relationship between Servant Leadership and Affective dimension of SWB

Table 8

Correlation of Servant Leadership and Affective Dimension

\begin{tabular}{lccccccc}
\hline Correlation & Mean & S.D & $\begin{array}{c}\text { Affective } \\
\text { Dimension }\end{array}$ & $\begin{array}{c}\text { Emotional } \\
\text { Healing }\end{array}$ & Empowerment & $\begin{array}{c}\text { Growth of } \\
\text { people }\end{array}$ & Conceptualization \\
\hline Affective Dimension & 3.983 & 1.381 & 1 & & & & \\
Emotional Healing & 4.353 & 1.487 & $0.525^{*}$ & 1 & & & \\
Empowerment & 4.297 & 1.407 & $0.365^{*}$ & $0.645^{*}$ & 1 & 1 & 1 \\
Growth of people & 4.431 & 1.34 & 0.034 & $0.266^{*}$ & $0.380^{*}$ & $0.503^{*}$ & 1 \\
Conceptualization & 4.8 & 1.215 & 0.081 & $0.343^{*}$ & $0.336^{*}$ & &
\end{tabular}

The final step was to construct structural model and perform regression analysis. Figure 4 represents the Structural Model, from which model fit and structural relationship has been estimated. The value for R2 for the estimated model is 0.26 (significant at $\mathrm{p}<0.001$ ) which shows that 26 percent variation in dependent variable is caused by independent variables. The standardized path coefficients $(0.40$ at $\mathrm{p}<0.001,-0.12$ at $\mathrm{p}>0.05$, 0.01 at $\mathrm{p}>0.05$, and -0.07 at $\mathrm{p}>0.05$ ) can be seen in figure 4 . 


\section{Figure 4}

Path Diagram for Servant Leadership and SWB (Affective Dimension) Model

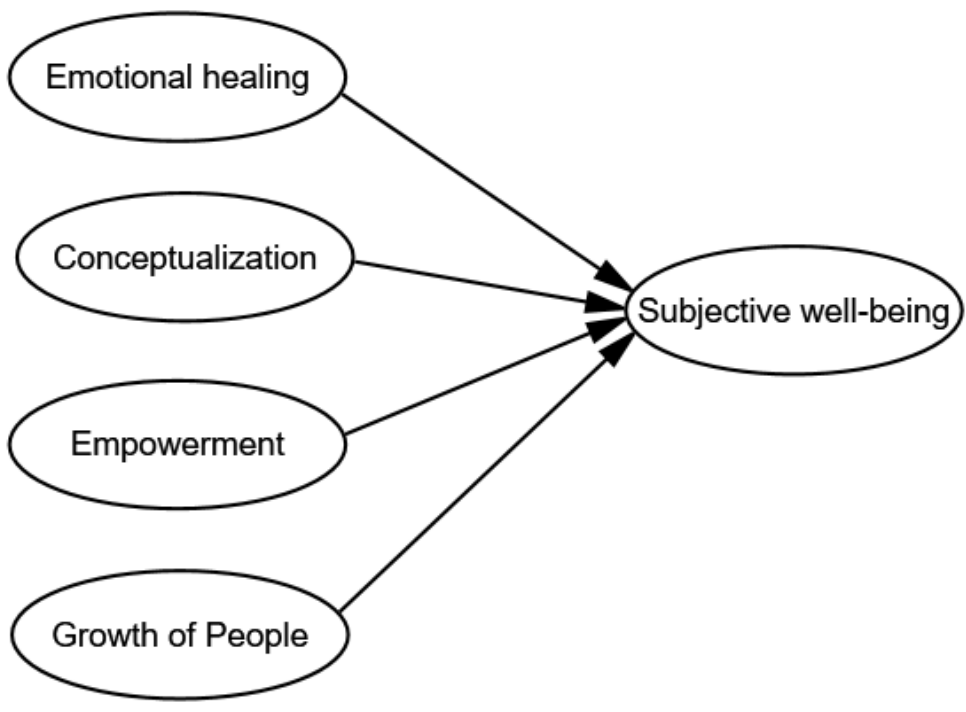

The overall model fit (as shown in Table 9) shows that model for servant leadership being predictor of SWB is a good fit model.

Table 9

\begin{tabular}{lcc} 
Measurement Model fit & \\
\hline Fit statistic & Acceptable Range & $\begin{array}{l}\text { Actual Output Servant leadership } \\
\text { and SWB (Affective Dimension) }\end{array}$ \\
\hline$\chi^{2}$ & - & 321.329 \\
Df & - & 156 \\
$\chi^{2}$ significance & $\mathrm{p}>0.05$ & 0 \\
$\chi^{2} / \mathrm{df}$ & $<5.00$ & 2.059 \\
GFI & $>.90$ & 0.906 \\
CFI & $>.90$ & 0.942 \\
RMSEA & $<.08$ & 0.059 \\
\hline
\end{tabular}

The summarized results for standardized coefficients are shown in Table (10). It is clear from the result that only Emotional Healing has significant positive impact on SWB. Whereas all other variables (conceptualization, empowerment and growth of people) have non-significant values.

Table 10

Regression Analysis on Servant Leadership (Dependent Variable =SWB (Affective Dimension)

\begin{tabular}{lcccc}
\hline Variables & Standardized Coefficient & Critical Ratio & Tolerance & VIF \\
\hline Emotional Healing & $0.67^{* * *}$ & 5.358 & 0.564 & 1.773 \\
Empowerment & -0.01 & -0.072 & 0.536 & 1.865 \\
Growth of People & -0.07 & -0.726 & 0.695 & 1.439 \\
Conceptualization & -0.12 & -.1 .272 & 0.699 & 1.431 \\
\hline
\end{tabular}


Multicollinearity was also checked to confirm that there is no issue of high correlation among independent constructs. The acceptable values for variance inflation factor (VIF) should be $<5$ and Tolerance $<1$ (Hair Jr et al., 2010; Tabachnick \& Fidell, 2007). So, the values in Table 10 are also within acceptable range which shows data doesn't have multicollinearity issue.

\section{Discussion}

In today's existing era the work force is facing an enormous amount of challenges especially those working in SMEs. The feelings and emotions of employees play pivotal role in the well-being of one's life. The correlation and regression results indicate that hypothesis postulated about relationship of emotional healing and affective dimension is affirmed. Table 9 shows that the value of correlation shows that the value of correlation $(\mathrm{r}=0.525)$ between emotional healing and affective dimension is significant as $\mathrm{p}<0.05$. In addition the value in regression model as obtained is $R_{2}=26$ percent significant at $\mathrm{p}<0.05$ also affirmed our assumption (see Table 10).

The correlational and regression analysis results obtained through service and manufacturing sector SMEs proved that emotional healing has a positive influence on the overall employees SWB. Servant leadership is built on the concept of prompting emotional health within organization. The results for emotional healing as an essential characteristic of servant leaders also helped to fill the gap suggested by Barbuto Jr and Wheeler (2006). Their study suggested that research opportunities should prevail to test the extent to which servant leadership fosters emotional health/ well-being.

Pressman and Cohen provide additional support evidences (Diener \& Chan, 2011; Pressman \& Cohen, 2005). Their study included psychologist who conferred that use of positive emotional words helped to increase life of their patients up to 4.2 years. By further extending research on Pressman and Cohen (2005) postulates Diener and Chan (2011) revealed that the positive feelings and emotion do have persuasive effect on subjective well-being and such positive feelings and emotions can further expand the life span of an individual. Further as argued by Harter et al. (2003) that decline in emotional involvement cause damage to wellbeing of individual therefore, leaders must anticipate in the process of providing emotional support to their workers.

It is further noted that altruism or altruistic calling helps leader to foster positive change in employee's life. This characteristic of servant leadership supports leader to develop not only individuals but also organizations, societies and communities (Avolio \& Locke, 2002). The second hypothesis of this study assumed that Altruism is positively related to Affective dimension. This assumption could not be tested for the reason that factor analysis reduced the dimension of servant leadership scale to only four dimensions and altruism was dropped due to improper factor loadings. Hence the second hypothesis was not endorsed for further analysis.

It has been evidenced that as employees in SMEs are the real player of their organizations who work under the closed supervision of their leaders therefore the basic role of empowerment remains detrimental. The third hypothesis formalized in the research is given as Empowerment is positively related to Affective dimension. 
The correlational and regression analysis tests were performed and outcomes of these tests proved the third hypothesis. In Table 11 it is clear that $\mathrm{r}=.365$ and in Table $R_{2}=26$ percent significant at $\mathrm{p}<0.05$ indicating that empowerment is positively related to affective dimension.

The results are consistent with the study outcome of Hussain and Ali (2012) that empowerment has positive link with workers' performance. These results are consistent with work of Byham and Cox (1999). According to their study, the role of empowering employees remains salient in enhancing organizational effectiveness and employees' well-being. The results of this study are also supported by Bocarnea and Dimitrova (2010) concluded that for servant leaders, empowerment is a tool for providing services to employees.

The provision of growth and development opportunities help employees of SMEs not only to excel in necessary skills and capabilities but also to raise their living standard as also articulated by Page and Wong (2000) that servant leader is a mentor who strives to facilitate subordinates for their personal development and well-being.

The fourth hypothesis postulated that Growth of people is positively related to Affective dimension. This relationship has been disapproved in results as correlation coefficient $(\mathrm{r}=0.034)$ was insignificant at $\mathrm{p}>0.05$.

Although several research studies also established a strong correlation among Growth of people, LMX, transformational leadership, additional struggle, organizational effectiveness, job commitment, job performance and organizational performance (Barbuto Jr \& Hayden, 2011; Melchar \& Bosco, 2010).

However, the results of this study have shown no relationship between the growth of people and SWB dimensions. The results can be justified on the fact that there is no concept of employee growth in SME sector of Pakistan. Training and development are less adopted practices in Pakistani SMEs, also career paths for SME employees are not well defined in this region (Raziq \& Khair, 2015). Batool and Zulfiqar (2011) suggested that government of Pakistan should take some initiative for training and development programs in SME sector.

The literature helped to build foundation for hypotheses five that Conceptualization is positively related to affective dimension. The correlation coefficient results for hypothesis five showed significant results as $r=0.081$ at $\mathrm{p}<0.05$. However, the regression analysis proved to be insignificant. Thus, the results of this study showed insignificant results indicating that there is no impact of conceptualization on Affective dimension of SWB of employees in SME sector.

Several research studies have shown significant relationships of conceptualization with other organizational outcomes. These studies showed that conceptualization has a valuable impact on employee performance, followers' organizational commitment, in-role performance and citizenship behavior (Liden et al., 2008; Towler, 2003). However, the results of this study showed insignificant results indicating that there is no impact of conceptualization on affective dimension of SWB of employees in SME sector. Moreover, the result for conceptualization is also consistent with the past investigation of Hussain and Ali (2012) where conceptualization has been found to have insignificant relationship with job performance.

The results can be justified on the basis that the lack of vision and planning and ig- 
norant behavior of leaders prevails in SMEs. Hence, they do not pay any consideration towards these aspects (Afraz, Hussain, \& Khan, 2014).

This research supports the concept presented by Burke et al. (2015) that subjective wellbeing of employees is related to servant leader as wellbeing is the core essence of servant leadership phenomenon. Therefore, this study affirms that servant leadership is not only linked with SWB besides that the study also suggest that provision of growth and conceptualization are the two major factors that are missing in the leadership profile of SMEs. As suggested by Batool and Zulfiqar (2011); Raziq and Khair (2015) that training and development initiatives should be the major focus in SMEs to deal with potential problems faced by this sector. Moreover, this study supports the conceptualization (Batool \& Zulfiqar, 2011; Raziq \& Khair, 2015) and suggest that in the current era leadership in SMEs have to provide more opportunities to workers for growth and have to build vision for the better future of their firms such factors can achieve higher results.

\section{Conclusion}

The objective of this research was to determine the relationship between servant leadership and Affective dimension of employee SWB in SMEs. For this purpose data were collected from both service and manufacturing sectors of SMEs. The responses from the employees of SME sector revealed that there is a positive relationship between Affective dimension of SWB and Servant leadership as emotional healing and empowerment were having positive relationship with SWB.

The correlation analysis results lead us to articulate that the leaders in SME sector have certain traits which contribute to the improvement of SWB. Such traits are also the basic characteristics of servant leadership which are fostering essential facet for workers well-being in affective term.

The SWB is based on two important aspects of human life such as affective and cognitive components. Both components help individuals to provide life satisfaction. However, through generation of positive feelings in ones' life the immediate leaders can remove trauma from their workers life. This event can take place when leader has importance for emotional stability of employees. The positive feelings and emotions leads toward healthy workforce which is not only productive but also capable of meeting the challenges effectively and efficiently. The servant leaders characteristics; of emotional healing and empowerment have been emerged as powerful tools for satisfying affective dimension of SWB.

The research result showed that three characteristics of servant leadership had significant impact on SWB of employees. These were emotional healing, empowerment and conceptualization whereas emotional healing had more noteworthy impact on Affective aspect of SWB than empowerment. Among other variables, altruism was excluded for further investigation as factor analysis resulted in removal of this factor. The growth of people was also proven to have no relationship with the SWB as a dependent variable. Whereas in regression analysis conceptualization proved to have no significant impact on affective dimension of SWB. Reason is that less importance is given to planning and 
building vision in SMEs. The utmost cause behind lack of vision and planning in SMEs is that owners/leaders due to ignorance and lack of education do not pay any consideration towards these aspects.

Growth of people also remained unimportant facet in SMEs of Balochistan; and the root causes of this negligence along with ignorance; are unavailability of needed resources, lack of training, and development programs, as well as facilities within whole region. These evidences lead us to make conclusion; that the leaders who possess traits such as, emotional healing and empowerment; nurtures employee's subjective well-being in small and medium enterprises.

Like other studies, this study also have some limitations. Firstly, there was unavailability of sampling frame for SMEs in Balochistan. Different institutions like SMEDA, Quetta Chamber of Commerce, has been contacted for this purpose but unfortunately neither of these institutions could provide the exact number, names and address of SMEs in Balochistan. Moreover, due to convenience sampling usage, representation of all workforce in small firms left unachieved. Secondly; there was reluctance of many small business owners for permitting researcher of this study for collection of data. Thirdly, many respondents refused to fill out questionnaires, which showed lack of awareness among people regarding research and its underlying benefits.

Finally, as a result of access issues, time constraints and dearth of resources, data were collected from two major cities of Pakistan (Hub and Quetta). Thus the, generalizability of results is limited.

This study has made significant contributions to the filed, as it has verified the underlying relationship between Servant Leadership and Subjective Well-Being of workers in SME sector. The phenomenon of servant leadership has been studied in different organizational setting with various organizational outcomes. However, there is a dearth of studies focusing on subjective well-being as well as in the context of SMEs. This study has tried to fill this gap.

On the other hand, the study has some limitations as well. As it has taken into account five characteristics of servant leadership which also provides gap for future studies to include more variables and test the relationship among other factors. Another limitation is selection of both service and manufacturing sector SMEs relating to diversified types. Future researchers can work on same topic and specify a particular sector for this reason to get more conclusive results. The third limitation of this study is focusing on affective dimension of SWB only. Future researchers can also work on cognitive dimension of SWB in order to get fully informed about the role of servant leadership in overall SWB of employees. 


\section{References}

Abid, H. R., Gulzar, A., \& Hussain, W. (2015). The impact of servant leadership on organizational citizenship behaviors with the mediating role of trust and moderating role of group cohesiveness; A Study of public Sector of Pakistan. International Journal of Academic Research in Business and Social Sciences, 5(3), 234-242.

Afraz, N., Hussain, S. T., \& Khan, U. (2014). Barriers to the growth of small firms in Pakistan: A qualitative assessment of selected light engineering industries. The Lahore Journal of Economics, 19(1), 135-176.

Arnetz, B. B. (1999). Staff perception of the impact of health care transformation on quality of care. International Journal for Quality in Health Care, 11(4), 345-351.

Avolio, B. J., \& Locke, E. E. (2002). Contrasting different philosophies of leader motivation: Altruism versus egoism. The Leadership Quarterly, 13(2), 169-191.

Barbuto, J., \& Gifford, G. T. (2010). Examining gender differences of servant leadership: An analysis of the agentic and communal properties of the servant leadership questionnaire. Journal of Leadership Education, 9(2), 4-21.

Barbuto Jr, J. E., \& Hayden, R. W. (2011). Testing relationships between servant leadership dimensions and leader member exchange (LMX). Journal of Leadership Education, 10(2), 22-37.

Barbuto Jr, J. E., \& Wheeler, D. W. (2002). Becoming a servant leader: Do you have what it takes? Cooperative Extension, Institute of Agriculture and Natural Resources, University of Nebraska-Lincoln.

Barbuto Jr, J. E., \& Wheeler, D. W. (2006). Scale development and construct clarification of servant leadership. Group \& Organization Management, 31(3), 300-326.

Barlett, J. E., Kotrlik, J. W., \& Higgins, C. C. (2001). Organizational research: Determining appropriate sample size in survey research appropriate sample size in survey research. Information Technology, Learning, and Performance Journal, 19(1).

Bass, B. M. (2000). The future of leadership in learning organizations. Journal of Leadership Studies, 7(3), 18-40.

Bastian, B., Kuppens, P., De Roover, K., \& Diener, E. (2014). Is valuing positive emotion associated with life satisfaction? Emotion, 14(4), 639-645.

Batool, S. A., \& Zulfiqar, S. (2011). The performance and structure of small \& medium enterprises: An empirical evidence from Pakistan. Pakistan Journal of Social Sciences (PJSS), 31(2), 433-447.

Bocarnea, M. C., \& Dimitrova, M. (2010). Testing servant leadership theory with Bulgarian students. International Journal of Leadership Studies, 5(3), 255-268.

Burke, R. J., Page, K. M., \& Cooper, C. L. (2015). Flourishing in life, work and careers: individual wellbeing and career experiences. Edward Elgar Publishing.

Byham, W. C., \& Cox, J. (1999). Zapp! the lightning of empowerment. Random House Business Books.

Campbell, A., Converse, P. E., \& Rodgers, W. L. (1976). The quality of American life: Perceptions, evaluations, and satisfactions. Russell Sage Foundation.

Clark, A. E. (1997). Job satisfaction and gender: Why are women so happy at work? Labour Economics, 4(4), 341-372. 
Comrey, A. L., \& Lee, H. B. (2013). A first course in factor analysis. Taylor \& Francis.

Diener, E., \& Chan, M. Y. (2011). Happy people live longer: Subjective well-being contributes to health and longevity. Applied Psychology: Health and Well-Being, 3(1), 1-43.

Diener, E., Colvin, C. R., Pavot, W. G., \& Allman, A. (1991). The psychic costs of intense positive affect. Journal of Personality and Social Psychology, 61(3), 492.

Diener, E., Wirtz, D., Biswas-Diener, R., Tov, W., Kim-Prieto, C., Choi, D.-W., \& Oishi, S. (2009). New measures of well-being. In Assessing well-being. Springer Netherlands.

Dolan, P., Peasgood, T., \& White, M. (2008). Do we really know what makes us happy? A review of the economic literature on the factors associated with subjective wellbeing. Journal of Economic Psychology, 29(1), 94-122.

Field, A. (2009). Discovering statistics using SPSS. Sage publications.

Fornell, C., \& Larcker, D. F. (1981). Evaluating structural equation models with unobservable variables and measurement error. Journal of Marketing Research, 39-50.

Gibson, T., \& Van der Vaart, H. (2008). Defining SMEs: A less imperfect way of defining small and medium enterprises in developing countries. Brookings Global Economy and Development.

Greenleaf, R. K. (1977). Servant leadership. New York: Paulist Press.

Griffin, M. A., Patterson, M. G., \& West, M. A. (2001). Job satisfaction and teamwork: The role of supervisor support. Journal of Organizational Behavior, 22(5), 537-550.

Gul, S., Rehman, S. U., Razzaq, N., Ahmad, B., \& Saif, N. (2012). Impact of leadership styles on organizational commitment in pharmaceutical companies of Pakistan. Paper presented at the Information and Knowledge Management.

Hair Jr, J., Black, W., Babin, B., \& Anderson, R. (2010). Multivariate data analysis: A global perspective. Pearson Prentice Hall.

Harter, J. K., Schmidt, F. L., \& Keyes, C. L. (2003). Well-being in the workplace and its relationship to business outcomes: A review of the Gallup studies. The Positive Person and the Good Life. Washington DC: American Psychological Association.

Hussain, T., \& Ali, W. (2012). Effects of servant leadership on followers' job performance. Journal For Science, Technology And Development, 31(4), 359-368.

Joshanloo, M. (2017). Mediators of the relationship between externality of happiness and subjective well-being. Personality and Individual Differences, 119, 147-151.

Khalique, M., Isa, A. H. M., Shaari, M., \& Abdul, J. (2011). Challenges for Pakistani SMEs in a knowledge-based economy. Indus Journal of Management E Social Sciences, 5(2), 74-80.

Khan, N. R., Awang, M., \& Zulkifli, C. M. (2013). Small and medium enterprises and human resource practices in Pakistan. International Journal of Asian Social Science, $3(2), 460-471$.

Khurrum, S., Rana, A. I., \& Asad, U. (2008). Owner characteristics and health of SMEs in Pakistan. Journal of Small Business and Enterprise Development, 15(1), 130-149.

Kibbe, M. R. (2015). Leadership theories and styles. In Leadership in surgery. Springer.

Kline, T. J., Sulsky, L. M., \& Rever-Moriyama, S. D. (2000). Common method variance and specification errors: A practical approach to detection. The Journal of Psychology, 134(4), 401-421. 
Klonowicz, T. (2001). Discontented people: Reactivity and locus of control as determinants of subjective well-being. European Journal of Personality, 15(1), $29-47$.

Laub, J. (1999). Assessing the servant organization: Development of the servant organizational leadership assessment (SOLA) instrument. In Servant leadership. Palgrave Macmillan UK.

Liden, R. C., Wayne, S. J., Zhao, H., \& Henderson, D. (2008). Servant leadership: Development of a multidimensional measure and multi-level assessment. The Leadership Quarterly, 19(2), 161-177.

MacCallum, R. C., Widaman, K. F., Zhang, S., \& Hong, S. (1999). Sample size in factor analysis. Psychological Methods, 4(1), 84-99.

Macik-Frey, M., Quick, J. C., \& Cooper, C. L. (2009). Authentic leadership as a pathway to positive health. Journal of Organizational Behavior, 30(3), 453-458.

Malhotra, N., \& Birks, D. (2006). Market research: An applied approach. Harlow: Pearson.

Marzuki, N. A. (2013). The impact of personality on employee well-being. European Scientific Journal, 9(20), 43-52.

Maula-Bakhsh, R., \& Raziq, A. (2013). Development of conceptual link between servant leadership \& employee subjective well-being. Journal of Applied and Emerging Sciences, 4(2), 157-168.

Maxwell, J. C. (2011). The 360 degree leader with workbook: Developing your influence from anywhere in the organization. Thomas Nelson Inc.

Mazzocchi, M. (2008). Sampling probability and inference statistics for marketing and consumer research. Sage publications.

Melchar, D. E., \& Bosco, S. M. (2010). Achieving high organization performance through servant leadership. The Journal of Business Inquiry, 9(1), 74-88.

Neubert, M. J., Hunter, E. M., \& Tolentino, R. C. (2016). A servant leader and their stakeholders: When does organizational structure enhance a leader's influence? The Leadership Quarterly, 27(6), 896-910.

Page, D., \& Wong, T. P. (2000). A conceptual framework for measuring servant leadership. University Press of America Boston, MA.

Panaccio, A., Donia, M., Saint-Michel, S., \& Liden, R. C. (2015). Servant leadership and wellbeing. Edward Elgar Publishing.

Parolini, J. L. (2004). Effective servant leadership: A model incorporating servant leadership and the competing values framework. In Proceedings of the servant leadership research roundtable.

Patterson, K. A. (2003). Servant leadership: A theoretical model. Regent University.

Pressman, S. D., \& Cohen, S. (2005). Does positive affect influence health? Psychological Bulletin, 131(6), 925-971.

Qureshi, J., \& Herani, G. M. (2011). The role of small and medium-size enterprises (SMEs) in the socio-economic stability of Karachi.

Raziq, A. (2011). High performance management practices in manufacturing and servicebased SMEs. A comparative study. In Proceedings of the 24th Annual Conference of the Small Enterprise Association of Australia and New Zealand (SEAANZ 2011).

Raziq, A., \& Khair, S. (2015). Exploring training and development practices in Pakistani SMEs. Buitems Journal of Social Sciences and Humanities, 1(1), 46-56. 
Raziq, A., Wiesner, R., et al. (2016). High performance management practices and sustainability of SMEs. Evidence from manufacturing and services-based industries in Pakistan. Journal of Management Sciences, 3(2), 83-107.

Russell, R. F., \& Gregory Stone, A. (2002). A review of servant leadership attributes: Developing a practical model. Leadership E Organization Development Journal, 23(3), 145-157.

Rynes, S. L., Colbert, A. E., \& Brown, K. G. (2002). HR professionals' beliefs about effective human resource practices: Correspondence between research and practice. Human Resource Management, 41(2), 149-174.

Saunders, M., Lewis, P., \& Thornhill, A. (2009). Research methods for business students. Pearsons education.

Sekaran, U., \& Bougie, R. (2016). Research methods for business: A skill building approach. United States: John Wiley \& Sons.

Sendjaya, S., \& Sarros, J. C. (2002). Servant leadership: Its origin, development, and application in organizations. Journal of Leadership \& Organizational Studies, 9(2), 5764.

Sims, B. J. (2005). Servanthood: Leadership for the third millennium. United States: Wipf and Stock Publishers.

SMEDA. (2007). SME Policy 2007. Ministry of Industries, Production E Special Initiatives Government of Pakistan.

Spears, L. C. (2005). The understanding and practice of servant leadership. International Journal of Servant Leadership, 1(1), 29-46.

Spears, L. C. (2010). Character and servant leadership: Ten characteristics of effective, caring leaders. The Journal of Virtues E Leadership, 1(1), 25-30.

Spector, P. E. (2012). Industrial and organizational psychology: Research and practice. United States: Wiley.

Tabachnick, B. G., \& Fidell, L. S. (2007). Using multivariate statistics. Allyn \& Bacon/Pearson Education.

Towler, A. J. (2003). Effects of charismatic influence training on attitudes, behavior, and performance. Personnel Psychology, 56(2), 363-381.

Ullah, H., Shah, B., Hassan, F. S. U., \& Zaman, T. (2011). Environment related factors affecting the entrepreneurial orientation. International Journal of Education and Social Sciences (IJESS), 1(1), 1-19.

Vaus, D. (2002). Surveys in social research. United Kingdom: Taylor \& Francis.

Winston, B. E. (2003). Extending Patterson's servant leadership model: Explaining how leaders and followers interact in a circular model. Unpublished manuscript presented at Servant Leadership Research Roundtable, Regent University, Virginia Beach, VA.

World Bank. (2015). Economic assessment report on Pakistan. Islamabad: World Bank. 